\title{
Seasonality of mortality: the September phenomenon in Mediterranean countries
}

\author{
Matthew E. Falagas MD DSc, Drosos E. Karageorgopoulos MD, Lambros I. Moraitis, \\ Evridiki K. Vouloumanou MD, Nikos Roussos MD, George Peppas MD, Petros I. Rafailidis MD MSc
}

Previously published at www.cmaj.ca

\section{ABSTRACT}

Background: Seasonal increases in the mortality rate have been associated with excessively cold or hot weather. We evaluated monthly patterns of mortality in selected countries.

Methods: We analyzed all-cause mortality statistics from 5 European Mediterranean countries (Cyprus, France, Greece, Italy, Spain), Sweden, North America (United States and Canada), Australia, New Zealand and Japan. We extracted and tabulated data on monthly all-cause mortality in the general population from the earliest to the latest year that records were available.

Results: We identified relevant data for a period of 2-57 years in each country. In the Mediterranean countries, the lowest average daily mortality was observed in September (all countries, 125/168 [74\%] years). The fewest deaths were in August in Sweden (14/20 [70\%] years) and North America (32/50 [64\%] years). The fewest deaths in Japan occurred in July (2/2 [100\%] years). In the southern hemisphere, the lowest mortality in Australia occurred in March (7/10 [70\%] years) and in February for New Zealand (cumulative over 24 years).

Interpretation: Mortality in the general population declines in the late summer to early fall months in the countries evaluated. Environmental parameters may partly account for these associations, and further research is needed on the contribution of additional factors such as summer vacations.

Une version française de ce résumé est disponible à l'adresse www.cmaj.ca/cgi/content/full/cmaj.090694/DC1

$\mathrm{L}$ arge-scale population studies have shown seasonal variation in mortality rates from various causes in different parts of the world. ${ }^{1,2}$ It has been observed that mortality peaks during the cold winter months. ${ }^{3}$ This observation has led to investigations of the specific causes of death that account for the excess mortality in winter and the underlying pathophysiological mechanisms. ${ }^{4,5}$ Human behavioural patterns, socio-economic factors and environmental parameters are thought to be related to seasonal variations in mortality. ${ }^{13,6}$ The elucidation of such associations can aid in the organization of relevant public health services.
In our practice, we have observed a consistent reduction in the number of patient visits during September for the last 10 years. We hypothesized that morbidity and subsequently mortality is decreased during September in Greece and probably in other countries with similar climatic and socioeconomic conditions.

\section{Methods}

We searched the Web for official statistical data on monthly mortality rates in various countries over the past 2-57 years. We focused on Greece, Cyprus, France, Italy, Spain, Sweden, the United States, Canada, Australia, New Zealand and Japan. We identified and retrieved relevant data from Eurostat, the US National Center for Health Statistics, Statistics Canada, the Australian Bureau of Statistics and the Japanese Bureau of Statistics. We also received electronic data from the New Zealand Health Information Service. We extracted and tabulated data on monthly all-cause mortality in the general population from the earliest to the latest year that records were available.

We adjusted the monthly mortality rates to the number of days per month to calculate the average daily mortality for each month of every year included in the country-specific data sets.

\section{Results}

A summary of the data retrieved and evaluated in our study is available in Appendix 1 (www.cmaj.ca/cgi/content/full /cmaj.090694/DC2). The monthly variations in mortality from the yearly average for the evaluated countries are shown in Figure 1.

For each of the 5 European Mediterranean countries included, the lowest average daily mortality occurred in September over the period for which relevant data could be

From the Alfa Institute of Biomedical Sciences (Falagas, Karageorgopoulos, Moraitis, Vouloumanou, Roussos, Peppas, Rafailidis); the Department of Medicine (Falagas, Rafailidis), Henry Dunant Hospital; the National Technical University of Athens (Moraitis); SOS Doctors (Peppas), Athens, Greece; and the Department of Medicine (Falagas), Tufts University School of Medicine, Boston, USA

Cite as CMAJ 2009. DOI:10.1503/cmaj.090694 
retrieved. Specifically, the lowest observed average daily mortality occurred in September for 4 of the 9 (44\%) years evaluated for Cyprus, 3 of the $11(27 \%)$ years for France, 42 of the $47(89 \%)$ years for Greece, 41 of the $57(72 \%)$ years for Italy, and 34 of the $44(80 \%)$ years for Spain. In Sweden, a northern European country, the lowest observed average daily mortality was in August for 14 of the 20 (70\%) years evaluated.

For both Canada and the US, the lowest observed average daily mortality occurred in August over the period for which data could be retrieved. Specifically, August had the lowest daily mortality for 10 of the $16(63 \%)$ years evaluated for Canada and 22 of the 34 (65\%) years evaluated for the US.

In Australia, the lowest observed average daily mortality occurred in March for 70\% of the years evaluated (7 of 10 years). In New Zealand, the lowest observed average daily mortality occurred in February for the entire 24-year period for which data could be retrieved. Monthly mortality data for each specific year were not publicly available.

In Japan, the lowest observed average daily mortality was in July for the 2-year period for which data could be retrieved ( 2 of 2 years [100\%]).

\section{Interpretation}

We found that the lowest monthly mortality rates in selected European Mediterranean countries over the last few decades occurred in September. In Sweden and North American countries, the lowest mortality occurred in August, while it occurred in July in Japan. In Australia and New Zealand, the lowest monthly mortality was in March and February, respectively, which correspond to September and August, respectively, in the northern hemisphere.

A potential explanation for the observed pattern of mortality is the association of mortality with environmental parameters, such as temperature. Several studies have reported the existence of an optimal level or range of environmental temperatures in which mortality in the general population is at its lowest. ${ }^{7-9}$ Studies have also identified excess mortality during the winter or summer months. ${ }^{3,5,6,9}$ Specifically, cold weather has been reported to be associated with increased risk of death from cardiovascular causes and respiratory infections. ${ }^{10,11}$ Excess heat is also associated with increased risk of death from cardiovascular and respiratory diseases, as well as external causes and gastrointestinal infections. ${ }^{4,6,8,9}$

The fact that many vulnerable individuals could die during summer heat waves could partly explain the lower mortality observed in September in the Mediterranean countries. However, we could not retrieve cause-specific monthly mortality data for the evaluated countries to examine this hypothesis. Improvements in housing conditions, which have led to less variability in indoor temperature with weather changes, could relate to diminishing seasonal variability in mortality. ${ }^{12,13}$

We speculate that summer vacations may also contribute to the lower mortality observed in September in the Mediterranean countries. Vacations can have both physiologic and psychological effects. Greater exposure to sunlight leads to increased synthesis of vitamin $\mathrm{D},{ }^{14}$ which may have beneficial effects for cardiovascular disease, renal failure, certain malig-

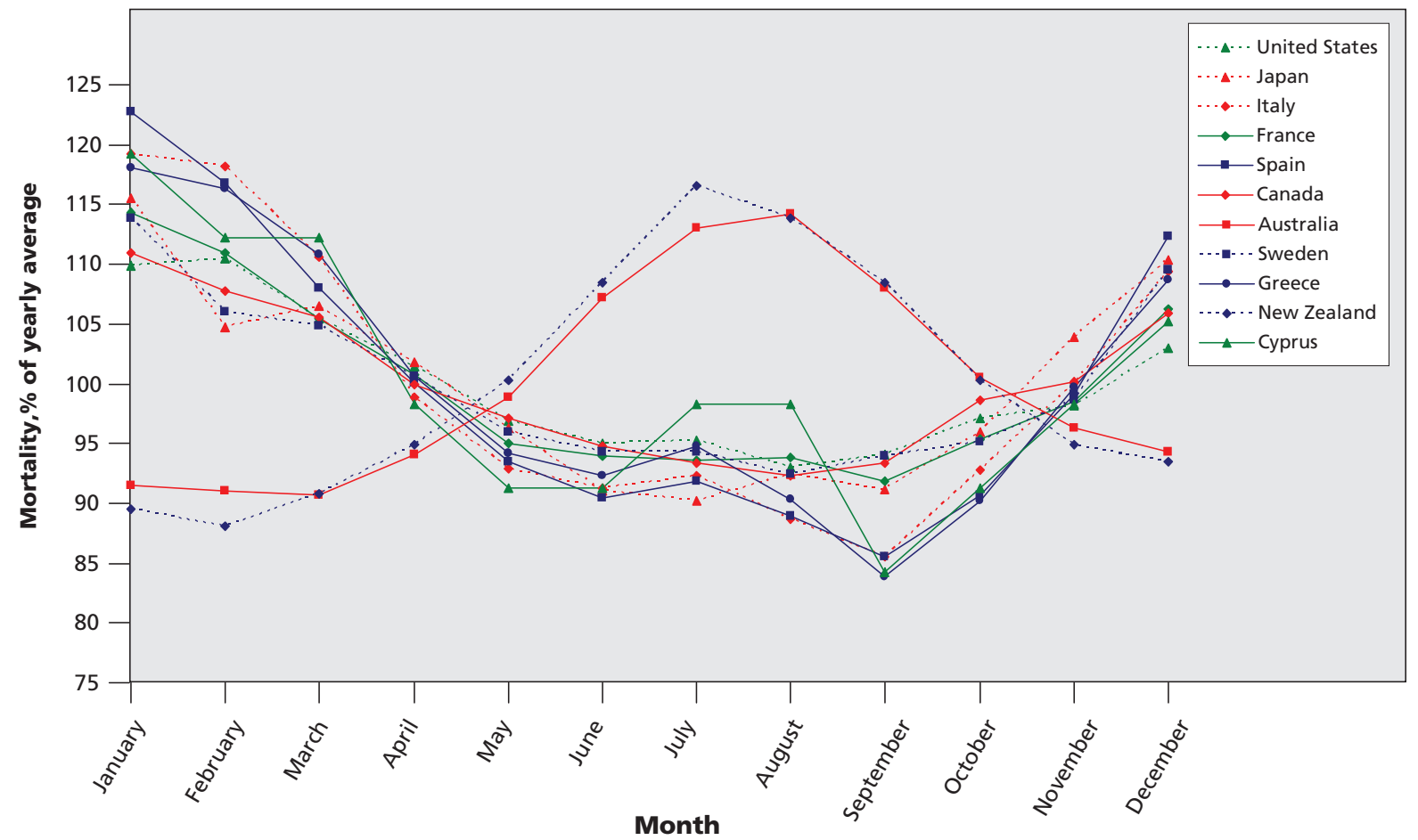

Figure 1: Monthly percentage variation in mortality compared to yearly average over the last years in European Mediterranean countries and other selected countries worldwide. Countries in the legend are listed according the absolute number of average deaths per day observed, in descending order. 
nant diseases, autoimmune disorders and infections, ${ }^{15-19}$ including influenza. ${ }^{20,21}$ The positive psychological effects of vacations consist of ameliorating mood, decreasing mental stress and providing a sense of recuperation and well-being, ${ }^{22-}$ ${ }^{24}$ that may last for at least a month after the vacation. ${ }^{24,25}$ Although the underlying mechanisms remain largely elusive, depressive mood and disappointing, untoward or stressful events have been associated with an increased risk of death, ${ }^{26}$ particularly from cardiovascular causes..$^{27,28}$

The difference between the Mediterranean countries and Australia and the remaining countries in terms of the specific month of the year with the lowest mortality could be related to differences in the timing or duration of summer vacations. ${ }^{29}$ Nonetheless, this factor may be insufficient to account for mortality differences in the general population because vacations are generally taken by a subset of the population. We could not retrieve monthly mortality data for specific age strata of the population in different countries to further test this hypothesis.

Differences in climate across different geographical regions could also explain the monthly mortality patterns observed in this study. ${ }^{30}$ Of note, coronary artery disease mortality in Los Angeles County, California, which has a milder climate compared with other US regions that resemble that of the Mediterranean countries, reaches its lowest level in September. ${ }^{31}$ Relevant data from northern European countries are in general agreement with our findings. Specifically, a study that jointly examined mortality data in England and Wales, the Netherlands, Denmark and Portugal showed that cardiovascular mortality was lowest at the end of August, and that mortality from all other causes was lowest in August through September. ${ }^{4}$ All-cause mortality reaches the lowest level during the August-September period in Germany. ${ }^{2}$ Mortality from cardiovascular disease in Norway and Ireland is lowest in August. ${ }^{32}$ In our study, we did not focus on these countries because this has previously been evaluated.

\section{Conclusion}

Data show that monthly mortality in the general population is lowest in September in the European Mediterranean countries that we evaluated, in March (the counterpart of September in the southern hemisphere) in Australia, in August for Sweden and North America, in February in New Zealand (the counterpart of August) and in July in Japan. These differences in mortality can be, in part, attributed to environmental factors, because adverse weather conditions, particularly excess cold or heat, are associated with greater risk of death. However, other less-appreciated factors may also account for the observed mortality patterns.

\section{This article has been peer reviewed.}

Competing interests: None declared.

Contributors: Matthew Falagas and George Peppas conceived the study. All authors contributed to the design of the study. Lambros Moraitis, Evridiki Vouloumanou, Nikos Roussos and Drosos Karageorgopoulos identified and analyzed the relevant data. Drosos Karageorgopoulos, Evridiki Vouloumanou, Petros Rafailidis and Matthew Falagas wrote the manuscript. All authors made substantial revisions and agreed with the final version of the manuscript.

Funding: No external funding was received for this research.

\section{REFERENCES}

1. Healy JD. Excess winter mortality in Europe: a cross country analysis identifying key risk factors. J Epidemiol Community Health 2003;57:784-9.

2. Lerchl A. Changes in the seasonality of mortality in Germany from 1946 to 1995 : the role of temperature. Int J Biometeorol 1998;42:84-8.

3. Cold exposure and winter mortality from ischaemic heart disease, cerebrovascular disease, respiratory disease, and all causes in warm and cold regions of Europe. The Eurowinter Group. Lancet 1997;349:1341-6.

4. Crombie DL, Fleming DM, Cross KW, et al. Concurrence of monthly variations of mortality related to underlying cause in Europe. $J$ Epidemiol Community Health 1995;49:373-8.

5. Keatinge WR. Winter mortality and its causes. Int J Circumpolar Health 2002;61: 292-9.

6. Ishigami A, Hajat S, Kovats RS, et al. An ecological time-series study of heatrelated mortality in three European cities. Environ Health 2008;7:5.

7. Ballester F, Corella D, Perez-Hoyos S, et al. Mortality as a function of temperature. A study in Valencia, Spain, 1991-1993. Int J Epidemiol 1997;26:551-61.

8. Kunst AE, Looman CW, Mackenbach JP. Outdoor air temperature and mortality in The Netherlands: a time-series analysis. Am J Epidemiol 1993;137:331-41.

9. Rocklov J, Forsberg B. The effect of temperature on mortality in Stockholm 1998 2003: a study of lag structures and heatwave effects. Scand J Public Health 2008; 36:516-23.

10. Eccles R. An explanation for the seasonality of acute upper respiratory tract viral infections. Acta Otolaryngol 2002;122:183-91

11. Barnett AG, Sans S, Salomaa V, et al. The effect of temperature on systolic blood pressure. Blood Press Monit 2007;12:195-203.

12. Lloyd EL, McCormack C, McKeever M, et al. The effect of improving the thermal quality of cold housing on blood pressure and general health: a research note. $J$ Epidemiol Community Health 2008;62:793-7.

13. Wilkinson P, Pattenden S, Armstrong B, et al. Vulnerability to winter mortality in elderly people in Britain: population based study. BMJ 2004;329:647.

14. Mora JR, Iwata M, von Andrian UH. Vitamin effects on the immune system: vitamins A and D take centre stage. Nat Rev Immunol 2008;8:685-98.

15. Dobnig H, Pilz S, Scharnagl H, et al. Independent association of low serum 25hydroxyvitamin $\mathrm{d}$ and 1,25-dihydroxyvitamin d levels with all-cause and cardiovascular mortality. Arch Intern Med 2008;168:1340-9.

16. Froicu M, Weaver V, Wynn TA, et al. A crucial role for the vitamin D receptor in experimental inflammatory bowel diseases. Mol Endocrinol 2003;17:2386-92.

17. Gibney KB, MacGregor L, Leder K, et al. Vitamin D deficiency is associated with tuberculosis and latent tuberculosis infection in immigrants from sub-Saharan Africa. Clin Infect Dis 2008;46:443-6.

18. Giovannucci E, Liu Y, Rimm EB, et al. Prospective study of predictors of vitamin D status and cancer incidence and mortality in men. J Natl Cancer Inst 2006;98:451-9.

19. Shoji T, Shinohara K, Kimoto E, et al. Lower risk for cardiovascular mortality in oral 1alpha-hydroxy vitamin D3 users in a haemodialysis population. Nephrol Dial Transplant 2004;19:179-84.

20. Bikle DD. Vitamin D and the immune system: role in protection against bacterial infection. Curr Opin Nephrol Hypertens 2008;17:348-52.

21. Laaksi I, Ruohola JP, Tuohimaa P, et al. An association of serum vitamin D concentrations $<40 \mathrm{nmol} / \mathrm{L}$ with acute respiratory tract infection in young Finnish men. Am J Clin Nutr 2007;86:714-7.

22. Chikani V, Reding D, Gunderson $\mathrm{P}$, et al. Vacations improve mental health among rural women: the Wisconsin Rural Women's Health Study. WMJ 2005;104:20-3.

23. Fritz C, Sonnentag S. Recovery, well-being, and performance-related outcomes: the role of workload and vacation experiences. J Appl Psychol 2006;91:936-45.

24. Westman M, Etzion D. The impact of vacation and job stress on burnout and absenteeism. Psychol Health 2001;1:95-106.

25. Strauss-Blasche G, Ekmekcioglu C, Marktl W. Does vacation enable recuperation? Changes in well-being associated with time away from work. Occup Med (Lond) 2000;50:167-72.

26. Gump BB, Matthews KA, Eberly LE, et al. Depressive symptoms and mortality in men: results from the Multiple Risk Factor Intervention Trial. Stroke 2005;36:98-102.

27. Trichopoulos D, Katsouyanni K, Zavitsanos X, et al. Psychological stress and fata heart attack: the Athens (1981) earthquake natural experiment. Lancet 1983;1:441-4.

28. Witte DR, Bots ML, Hoes AW, et al. Cardiovascular mortality in Dutch men during 1996 European football championship: longitudinal population study. BMJ 2000;321:1552-4.

29. Alesina A, Glaeser E, Sacerdote B. Work and leisure in the US and Europe: Why so different? National Bureau of Economic Research Working Paper Series No 11278. Cambridge (MA): The National Bureau of Economic Research; 2005.

30. Kalkstein LS, Greene JS. An evaluation of climate/mortality relationships in large U.S. cities and the possible impacts of a climate change. Environ Health Perspect 1997; 105:84-93.

31. Kloner RA, Poole WK, Perritt RL. When throughout the year is coronary death most likely to occur? A 12-year population-based analysis of more than 220000 cases. Circulation 1999;100:1630-4.

32. Eng H, Mercer JB. Seasonal variations in mortality caused by cardiovascular diseases in Norway and Ireland. J Cardiovasc Risk 1998;5:89-95.

Correspondence to: Dr. Matthew E. Falagas, Alfa Institute of Biomedical Sciences, 9 Neapoleos St., 15123 Marousi, Athens, Greece; fax 30 210-68-39-605; m.falagas@aibs.gr 